\title{
Factors that impact on access to water and sanitation for older adults and people with disability in rural South Africa: An occupational justice perspective
}

\author{
Laura Wrisdale ${ }^{1}$, Matodzi Michael Mokoena ${ }^{2}$, Lutendo Sylvia Mudau ${ }^{2}$ and Jo-Anne Geere ${ }^{1}$ \\ ${ }^{1}$ School of Health Sciences, Faculty of Medicine and Health Sciences, University of East \\ Anglia, Norwich Research Park, Norwich, United Kingdom \\ ${ }^{2}$ Department of Environmental Health, Tshwane University of Technology, South Africa \\ Corresponding author: Jo Geere, Physiotherapy Lecturer. Room 2.10, The Queen's Building, \\ School of Health Sciences, Faculty of Medicine and Health Sciences, \\ University of East Anglia, Norwich Research Park, Norwich, United Kingdom, NR4 \&TJ \\ Email: jo.geere@uea.ac.uk Telephone: +4401603 591011
}

\begin{abstract}
Limited access to water and sanitation is a risk to health, dignity and ability to engage in occupations. This article aims to: 1) discuss the current and historical factors affecting access to water and sanitation in rural South Africa, and 2) explore the occupational implications of water access, particularly for older adults and people with disability in rural South Africa. A literature review was carried out through searching MEDLINE, Scopus and JSTOR databases and using framework analysis to interpret documents retrieved. This paper also reports thematic analysis of semi-structured interviews, conducted in 2012 in a rural area of South Africa. Environmental, political, social-economic and attitudinal factors were identified as impacting on water access and occupation, in both the documentary analysis and the semi-structured interviews. Due to South Africa's history, injustice has occurred in the forms of occupational apartheid and occupational deprivation. We argue that supply systems must enable people to easily access more water than is required for simple subsistence. This is because access to water beyond the minimum quantity essential for survival is necessary for people to participate in meaningful and productive occupations. Therefore, access to water should be considered part of an occupational right. Recognising this right will be an integral step in ensuring that levels of water supply service are improved to support better livelihoods, economic and social empowerment and quality of life for all, in line with many of the new Sustainable Development Goals.
\end{abstract}

Key words: water, sanitation, disability, older adults, history, occupational justice Word count: 9,955 (excluding appendices)

\section{Acknowledgements}

Dr Roger Few provided intellectual contribution to the conceptualisation of the qualitative research with key informants. The qualitative interviews were conducted during a study funded by the U.K. Department for International Development http://r4d.dfid.gov.uk/pdf/outputs/water/61005-

DFID_HH_water_supplies_final_report.pdf The funder had no role in study design, data collection and analysis, decision to publish, or preparation of the manuscript. The funder did comment on the initial draft of the contract report (see above link). 


\section{Introduction}

Although the Millennium Development Goals have been hailed as "the most successful anti-poverty movement in history", progress has been uneven and inequalities endure (United Nations, 2015, p.3). The United Nations (2015) reported that the Millennium Development Goal target 7c, which aimed to halve the proportion of the global population without sustainable access to safe drinking water, was met five years ahead of schedule. 'Safe' drinking water is water obtained from a source considered unlikely to be contaminated with faeces or other pollutants (UNICEF \& WHO, 2015). However, even with this achievement, in 2015 the proportion of the global population who access unsafe drinking water equates to approximately 663 million people (UNICEF \& WHO, 2015). Particularly in sub-Saharan Africa, most of those who access unsafe water, together with many of those who do access 'safe' water, must still carry their water home from off-plot sources (Evans et al., 2013; UNICEF \& WHO, 2015).

The South African government have defined an acceptable basic level of service of safe drinking water, as a piped water supply to within 200m of a dwelling (AMCOW, 2011 ) and in 2013 it reported that $85.9 \%$ of households had access to piped water supplies (StatsSA, 2014). The 200m water standard was experienced during apartheid and has continued in the current era (DWA, 1994, 2005), however Majuru et al., (2012) indicated that the actual round trip distance to water points in rural areas of South Africa can be 600 meters or more. Within this high level of 'coverage' or access to piped water, the minimum standard allows inclusion of households in which people must still carry water home from the supply or access point, with $15.2 \%$ of households relying on water from communal taps, $2.6 \%$ from neighbour's taps and $4.2 \%$ from surface water. In 2013, the Limpopo province had the poorest access to water, with $62.1 \%$ of households reporting interruptions to municipal supply lasting more than 2 days at a time or for more than 15 days in the preceding 12 months (StatsSA, 2014). In households with off-plot supply, or with unreliable services, people may struggle to access water (Evans et al., 2013; Majuru, 2015) which impacts on their ability to engage in essential and meaningful occupations.

It is also acknowledged that disparities in the distribution of water persist, particularly among disadvantaged groups of people (Jones, 2013). People with disabilities represent one of the largest socially excluded groups, and in low and middle income 
countries, they have disproportionately limited access to water and sanitation (WaterAid, 2011). These limitations can have significant health implications; reports show that due to inadequate access people with disabilities consume less water, can be subject to physical, verbal and sexual abuse, and are at a higher risk of disease, infection and poverty (Groce, Bailey, Lang, Trani, \& Kett, 2011; WHO, 2011). The South African Human Rights Commission reported in 2013 that the impact of poor water and sanitation services disproportionately affects women, children and people with disability (Govender, 2014). Older adults in rural South Africa, particularly those on low incomes, have also been highlighted as vulnerable to water insecurity when water supply service levels are poor or unreliable (Geere, Hunter, \& Jagals, 2010a; Majuru, 2015; Mudau, 2016) and they frequently must also contend with disability linked to age related changes in health. Furthermore, difficulties have been observed in families affected by ill-health due to HIV/AIDS, either child headed households, or households in which the mother could no longer access sufficient volumes of water, and depended on the children to collect water. This resulted in absenteeism from school and hence infringed upon children's rights to education (Hemson, 2007; Makaudze, du Preez, \& Potgieter, 2008).

The evidence that unsafe drinking water and poor sanitation affect health is very strong (Bartram, Lewis, Lenton, \& Wright, 2005; Fewtrell et al., 2005; Prüss-Üstün, Bos, Gore, \& Bartram, 2008; Wang \& Hunter, 2010), however much less attention has been paid to how unsafe water or the work of fetching water from supply points outside of the home impacts on people's ability to engage in essential or meaningful occupations. Water is needed for people to be able to live well and function and participate in diverse occupations, and it also forms a significant component of selfcare occupations, such as washing, cleaning and maintaining personal hygiene. An occupational perspective is therefore a useful addition to the public health, economic and development discourse surrounding access to water and sanitation, because it highlights the need to improve access to resources and services beyond the minimum required for survival, and takes into consideration levels of water access required to meet diverse needs and preferences for occupation across the lifespan.

Further, the United Nations Sustainable Development Goal (SDG) 8 is to 'promote inclusive and sustainable economic growth, employment and decent work for all' by 2030. Wilcock and Townsend (2009, p. 193) defined occupational justice as 'the right 
of every individual to be able to meet basic needs and to have equal opportunities and life chances to reach toward her or his potential, but specific to the individual's engagement in diverse and meaningful occupation.' Whalley-Hammel and Iwama (2012) described an 'occupational right', as the right to engage in meaningful occupations, which links to occupational justice and adds to the focus of SDG 8 on economic growth, employment and decent work. Unsafe or limited water and sanitation access can be a barrier to essential occupations, such as self-care, but also affect people's ability to engage in other meaningful or productive occupations for various reasons, such as poor health (Geere, 2015), time lost due to water fetching (Geere, Mokoena, Jagals, Poland, \& Hartley, 2010b) or inability to maintain expected standards of personal presentation and hygiene. For example, limited access to water and sanitation can prevent children going to school and adults accepting certain jobs (Groce et al., 2011). This indicates that to meet SDG 8 and achieve occupational justice, improvements to water supply must provide access beyond that required for survival and simple subsistence. Improvements must also enable fulfilment of occupational rights for all, including people with disabilities, children and older adults, who are particularly vulnerable to occupational injustice and inequality when it comes to their access to safe water and sanitation (Govender, 2014). Wilcock and Townsend (2000) maintain that in occupationally just environments people have equal and sufficient access to resources to allow them to engage in meaningful occupations; however, occupational injustice ensues when people are deprived of the necessary resources and opportunities to participate in these occupations (Wolf, Ripat, Davis, \& MacSwiggan, 2010). Without access to sufficient water and sanitation it is difficult to understand how occupational justice can be achieved. The concept of occupational justice is therefore a useful lens through which to frame the impact of access to water and sanitation facilities, because it emphasises the human right to resources beyond the basic minimum required for survival and can be used to argue for levels of service which support participation in society, economically productive livelihoods and meaningful occupations across the lifespan.

Investigations into access to water and sanitation for people with disabilities have been conducted in Uganda and Zambia (Wilbur, 2014), and low and middle income countries more broadly (Groce et al., 2011; Jones \& Reed, 2005) The development discourse on inequality has addressed complex issues which can limit people's ability 
to access resources (Sen, 2001) and it is clear that institutional or social discrimination is a potent process which may disadvantage vulnerable groups from access to resources including water (Govender, 2014). However, despite the work of Sen, most research into access to water and sanitation for people with disability or older adults living in low income settings tends to focus on existing barriers and current statistics rather than questioning historical factors which have influenced how inequality has been produced and maintained in a specific context (Hansen \& Sait, 2011). In order to understand existing barriers it is important to investigate the past (Coclanis, 2015) and this is especially pertinent for South Africa, where many of the structures formed during the apartheid era continue to perpetuate poverty and inequality (Dube, 2005). Govender's (2014) first key finding stated 'Areas which lack water and sanitation mirror apartheid spatial geography.' Therefore, it is important to reflect on history to understand the roots of inequalities, and to consider the impact on access to water and sanitation, particularly for vulnerable groups such as people with disabilities or older adults living on low incomes.

This paper aims to expand scope of thinking by taking an occupational justice perspective to highlight how limited access to water and sanitation can impact on occupational participation, particularly for older adults or people with disability, living in rural South Africa. This is pertinent in light of many of the new Sustainable Development Goals including 1, 3, 6, 8 and 10, which aim to end poverty, ensure healthy lives and promote wellbeing for all, ensure access to water and sanitation for all, decent work and economic growth for all and reduce inequalities by 2030 (UN, 2016).

The research questions addressed in this study are:

1) What are the current and historical factors affecting access to water and sanitation in rural South Africa?

2) What are the occupational implications of access to water and sanitation for older adults or people with disability living in rural South Africa?

\section{Methodology}

Data were collected from two key sources of information. 
1) A review of published literature was conducted, to enable analysis of documents reporting factors which affect access to water and sanitation in South Africa. The review focussed on the period 1948 to 2014 to include both the apartheid era (1948-1994) and twenty years of the democratic era (19942014), up until the most recent general election in 2014. Both eras are pivotal moments in South Africa's history; the apartheid era created inequality and the democratic era began the process of dismantling it. As the 2014 general election was South Africa's fifth democratic election, it is an important time to reflect on South Africa's history and what has been achieved so far.

2) A set of six key informant interviews and two group interviews which were conducted at the beginning of a cross sectional survey comparing the health and social impacts of at-house versus off-plot water supplies in three villages of Limpopo Province, South Africa (Evans et al., 2013). The interviews were conducted to gain understanding of historical and contextual factors affecting access to water supply and sanitation facilities in the study communities. Key informants who could recall and offer special insight into the impact of changes to water supply and sanitation services within the study communities were invited to participate. The sample included people with disabilities, carers of people with disabilities, older adults, or local councillors who were elderly and resided in the study area. They were selected because of their insight into issues affecting access to water in their community, and particularly the situation for vulnerable groups. People with disability and carers of people with disability were included to ensure representation of people with personal, relevant experience of how people with disability access and are affected by water and sanitation services. We also ensured representation of older adults, as disorders associated with aging are a significant cause of disability in low and middle income countries, particularly for those living in rural areas with limited access to health services (Hoy, Geere, Davatchi, Meggitt, \& Barrero, 2014) and because older adults were highlighted as vulnerable to water insecurity in a previous pilot study in the same region (Geere et al., 2010a). There is also an increasing demand to mainstream both disability and aging in water and sanitation programmes ( Jones, 2013). 


\section{Literature review and documentary analysis}

The literature review was conducted to provide data which would help to put the interviews in context and obtain a broad picture of the macro environmental factors. A search was carried out in April 2015 using Journal Storage (JSTOR), Scopus and MEDLINE databases. These databases were selected in order to retrieve sources from a range of disciplines, including history, economics, politics, geography, law and health. A search was conducted by combining 'and' with the following terms:

- "South Africa"

- "water or sanitation"

- "histor* or politic* or policy or law or legislation"

- “disab* or impairment or 'older people' or elderly or senior"

These words were selected in order to capture the country (South Africa), the resource (water or sanitation), factors (historical and current) and the population (people with disabilities and older adults). Variations of the terms were used in an attempt to obtain all relevant literature. The JSTOR interface limits the number of words used in the search and thus requires a more concise search. For this reason, the words "law, legislation and older people" were removed as these had minor effects on the search results. The search terms were searched for in the title, abstract and key words in Scopus and MEDLINE. Since JSTOR articles do not all have abstracts, the term "South Africa" was searched for in title and the rest of the terms were searched for in the full text.

Inclusion criteria for the literature review were:

- study population residing in South Africa

- access to water and/or sanitation is a focus of the paper

- people with disabilities or older adults included in the paper

- timeframe 1948-2014 (includes apartheid and democratic era)

Framework analysis was used to provide a "systematic process of sifting, charting and sorting material according to the key issues and themes" (Ritchie \& Spencer, 1999). The analysis followed five stages to ensure a systematic approach. These include: 1) familiarization, 2) identifying a thematic framework, 3) indexing, 4) charting, 5) 
mapping and interpretation. Framework analysis was selected as it can be informed by priori reasoning and permits previously identified questions or issues to be considered in the analysis, while allowing new themes to emerge from the data. After the familiarization process the following questions were identified:

- What natural and man-made environment factors have affected access to water and sanitation?

- How has the 'legacy of the apartheid' affected access to water and sanitation?

- What political factors have affected access to water and sanitation since the Apartheid?

- What economic factors have affected access to water?

- What social factors have affected access to water and sanitation?

The data was then indexed and charted within a framework table, headed by these questions. This facilitated the mapping and interpretation of the data where potential answers to these questions emerged.

\section{Semi-structured Interviews}

A 'snowballing' technique was used to accumulate the sample where a researcher had discussions with household survey participants, local community researchers and interview participants about the people in the community. This was an appropriate method to include people with disability, as people with disabilities in low and middle income countries can be difficult to locate due to discrimination and consequential social isolation (WHO, 2011). Key informants were selected according to the following criteria:

1. An individual normally residing within the study survey area

2. An individual with understanding of how water for their own household's needs is usually supplied and accessed for use by household members

3. An individual with unique insight into the impact of water access and service levels on community members vulnerable due to disability or age, because of

a. Their own disability or role as a carer for a person with disability or

b. Older age and low income or

c. A person of older age with a role as a community councillor, to whom other community members voice problems 
When the key informants were identified they were provided with verbal and written information about the study, given the opportunity to ask questions and then invited to take part. Once consent had been obtained a suitable time and place for the interview was arranged. Interviews were audio-recorded, fully transcribed and translated into both English and Tshi-Venda. These primary sources were used in an attempt understand the factors affecting access to water and sanitation, particularly for older adults and people with disabilities.

Semi-structured interviews were conducted where the interviewer asked the participants about: 1) things that had happened in their lifetime to them or their village that they felt were important, 2) current issues in their community that they feel are important, and 3) their hopes for the future. The participants could relate their responses to any issue and were then also asked about water issues and people that they felt faced challenges with access to water in particular. There was an interpreter to translate the questions (asked in English) into the local language and to relay the answers back in English for the interviewer to respond. The interviews were transcribed and translated into English.

Data were analysed using thematic analysis as it provides a systematic approach for “identifying, analysing, and reporting patterns within data" (Braun \& Clarke, 2006, p. 6). The analysis was completed by one researcher who followed six key stages: 1) familiarisation of the data; 2) coding the data; 3) searching for themes; 4) reviewing themes; 5) defining and naming themes; and 6) reporting the information.

Interpretations of the data were discussed with the researchers who had conducted and translated the interviews, to explore alternative explanations of transcript content. It was a recursive process and involved moving back and forth between the data, the coding and the different factors. This flexibility is permitted and encouraged in the analysis as it promotes a rigorous approach (Braun and Clarke, 2006).

Ethical approval for the study was obtained from the University of East Anglia, Tshwane University of Technology and local chiefs of the participating villages. All participants gave informed consent or consent was obtained from a guardian if they were under the age of eighteen (Evans et al., 2013). 


\section{Findings}

\section{Literature search results}

The search yielded two hundred and thirty three papers. The selection process was completed independently by one researcher (figure 1). The search result suggests that there is limited research on historical factors affecting access to water and sanitation for older adults and people with disabilities in South Africa. The seven papers are mainly narrative reviews, including two scholarly reviews, two conference papers, two empirically based articles and one book chapter. The papers offer different insights into the interplay of factors: Van Koopen and Jha (2005) and Frances (2005) offer a broad view of the law and the political climate, Brown $(2011,2013)$ provides a political focus in a geographical context, Von Schnitzler (2008) presents an urban and economic perspective, and Bannister (2004) and Matsebe's (2006) conference papers focus on barriers for people with disabilities in particular (appendix 1).

\section{Documentary Analysis Findings}

From the framework analysis factors relating to the natural and man-made environment, the 'legacy of the apartheid' and political, economic and social factors since the apartheid, were identified as affecting access to water and sanitation. These findings are summarized below.

i. Environmental factors (natural and man-made)

South Africa is a water scarce country making access to water challenging from the outset. However, instead of populations settling around water sources, human settlement in South Africa developed around mineral deposits creating 'geographical inertia' (Brown, 2013, p.271) and incompatibility between water demand and water availability (Francis, 2005). This geography of water was perpetuated during the apartheid where huge disparities across the country in terms of access to water and sanitation developed, particularly in rural and peri-urban communities where water has been less accessible (Van Koopen and Jha, 2005; Francis, 2005). Furthermore, pollution levels have risen over the years due to faecal contamination and industrial and mining sectors expanding (Francis, 2005). Such pollution is a barrier to access and could be detrimental to health. For those who do not have water piped to their premises, or when supply systems break down (StatsSA, 2014), obtaining sufficient safe water to support essential or meaningful occupations requires that environmental 
challenges, such as walking up and down steep slopes or over distance to functioning public taps, are overcome (Geere et al., 2010a). Environmental factors therefore create substantial barriers to water access and occupational engagement for people with disability or older adults who have problems with mobility.

ii. The 'legacy of the apartheid'

Under the apartheid around three and a half million black people were forced to resettle in to territories called 'homelands' (Brown, 2013; Van Koppen and Jha, 2005). Not only did these areas tend to be where there was low and irregular rainfall with limited access to water, but they became weak economically (Brown, 2013; Francis, 2005; Van Koppen and Jha, 2005). Conversely, infrastructure projects, such as dams, irrigation systems and subsidized schemes, supported white populations and industries (Brown, 2013; Van Koppen and Jha, 2005). Thus "first-world and thirdworld economies developed side by side" (Francis, 2005, p.154). This was enforced by apartheid law and facilitated separate social development, where the black population had limited experience of irrigated farming, resource management, participatory governance and above all, education (Brown, 2011). Such limitations have disempowered and put the black population at a historic disadvantage. Thus the legacy of the apartheid and its 'separate development' entrenched the geography of water and established inequitable social stratification and access to water. The challenges linked to accessing sufficient water to engage with meaningful occupation in older age or when living with disability are therefore additional to a historical disadvantage for people in or from former 'homelands'.

iii. Political factors

Many of the articles recognise the progressive nature of The National Water Act (NWA) (1998) and the great potential that it has as a tool to redress inequities of the past (Brown, 2011, 2013; Van Koppen and Jha, 2005; Francis, 2005). Under the NWA water became recognised as a 'national asset' and private ownership of water was abolished (Brown, 2011, p.174). The act established a decentralised participatory model where Catchment Management Agencies were set up in nineteen areas; they were set up to be self-financing, with public participation representing the rights of all water users (Koppen and Jha, 2005). However, despite being a progressive form of legislation some local organisations have been unsuccessful due to insufficient 
funding for water resource management (Francis, 2005), poor technical planning (Bannister, 2004) and conflicting interests amongst a heterogeneous population (Brown, 2013). Furthermore, de facto rule of apartheid-era actors appears to continue (Brown 2011, 2013; Francis, 2005) and participatory meetings are not always inclusive of vulnerable groups (Brown 2011, 2013; Koppen and Jha, 2005). There has been limited provision of infrastructure that addresses the needs of people living with a disability which would enable them to access sufficient water and engage in occupations which require access to water (Bannister, 2004, p.59).

iv. Economic factors:

In 1996 the government adopted neoliberal policies, which embraced free markets, globalisation, privatization, cost recovery and restrictions on public spending, in an attempt to attract foreign investment and encourage economic growth. However, such economic measures frame water as a commodity and not a right. As Francis (2005) and Von Schnitzler (2008) point out, neoliberalism and lack of state assistance can have devastating effects, exacerbating poverty rather than alleviating it. As part of South Africa's cost recovery policy, the provision of water needed to be paid for through fees. However, many citizens have not been able to afford the fees, which, according to Francis (2005, p.170), has resulted in "increasing household debt, widespread water service cut-offs, citizen unrest and cholera epidemics". In some parts of the country pre-paid meters were installed, which required citizens to pay for water before it was allocated. For many people in these areas, water is subject to the availability of funds and requires constant scrutiny of their daily practices and water consumption (Von Schnitzler, 2008). Furthermore, some water services are being operated by private companies who aim to increase profit and do not always consider the needs of vulnerable groups of people (Francis, 2005). Although South Africa has a Free Basic Water Policy, which attempts to guarantee a minimum basic "lifeline" of potable water, it has been a "distant ideal" for millions (Van Koppen and Jha, 2005, p.205). There is evidence that in Limpopo, this 'lifeline' minimum quantity of 25 litres per person per day is rarely accessed for free (Majuru, 2015), and is not sufficient for people to easily engage in meaningful occupations, such as home gardening, or playing sport (Geere et al., 2010a; Geere et al., 2010b). 


\section{v. Social factors:}

There are huge disparities in power and wealth across the country; approximately five percent of the population controls eighty percent of the country's wealth (Francis, 2005, p.160). Poor communities have historically been excluded from water management and have had limited education which would enable them to do so effectively (Brown, 2011). Such inequality has the potential to marginalise and exclude vulnerable groups from access to the country's resources. Furthermore, Bannister (2004, p.59) reported that there has been a stigma around disability and a fear that disability can be "transferred to others". These attitudes are barriers to inclusion and access to water and sanitation. Lack of access to water and sanitation, resulting from social factors such as these, have the potential to cause and keep people in a state of poverty. Living in poverty increases the likelihood of injury and impairment and is a risk to health, dignity and occupational engagement.

\section{Findings from the interviews}

Through thematic analysis environmental, political, socio-economical and attitudinal themes were identified. Table 2 (appendix 1) provides a list of key quotes and information about each participant to support each theme.

i. Environment impacts on ease of water access and water quality for essential and productive occupations

The physical environment, and the location in which people live, makes people's access to water difficult and challenges their ability to engage in essential occupations, such as bathing, washing or cooking (interviews $5,7,8$ ) or productive occupations, such as growing food (interview 8). For example, some villagers have to travel long distances to access alternative or unsafe water sources, such as rivers, whilst others have to climb a hill once they have collected the water. Participants' comments included:

"Here at home if there is no firewood you must go and fetch the firewood if there is no water you must go to the fountain (spring) it's a problem. We did not bath this is not the colour of my skin." and "It is difficult to climb this hill. I cannot carry (20 litre water containers) because of this hill, if it is a flat area you can put them in a wheelbarrow." (interview 5) 
Interviewee: "It is water shortage, all these taps do not have water and it is already a month now without water."

Interviewer: "Does this happen everytime or is it just happening now?"

Interviewee: "It happens most of the times, the machines that have been placed initially have been placed down and when they have to make pressure to pump water up they always break down."

Interviewer: "Where do you normally get water?"

Interviewee: "It is at the main river." (interview 7)

Interviewee "They have problems those people because they fetch water down the hills, you must also remember that when they fetch water down the hills and take it up the hills they encounter problems, after some years you would hear people complaining about their backs."

Interviewer: "Do they have any challenges with the capacity of water that they are taking home?"

Interviewee: "It has a very big problem because they will have to cook, wash and bath and at the same time they are using 20 litre containers," (interview 7)

"It is a challenge for those who stay over the hill, they are suffering," (interview 8)

"There is something that I need to explain, I had developed a culture of avocados using water at my home, when I got the tap in my home in the beginning when I was still working I planted the avocado trees and even ploughing at an empty space and I was able to water the plants using that tap. Now I am suffering, I am an elderly person, now I can no longer carry the bucket of water and there is no water at the reservoirs, when water comes, it would only reach this house and not the next house, there are people who are connecting water illegally and the water is not reaching our homes and we do not know what to do anymore" (interview 8)

Thus the physical terrain can hinder access and reports show that carrying the water can be problematic for people's backs and difficult for older adults or those who have a disability. This impacts on a person's time, energy and physical capacity to engage with essential or productive occupations. Furthermore, there are also accounts of poor 
road conditions with an increasing number of potholes hindering access, particularly for people who use wheelchairs and already struggle with the steep slopes in the village. Indeed, because of this terrain it was reported that a person with a disability is forced to "crawl with her knees" to get to her destination (interview 6). It was explained that because the place where the wheelchair could be used was steep, "she needs somebody who is strong and can manage to brake it and drive it slowly downhill”. It would be extremely difficult or impossible for that individual to access and bring home water from a public standpipe, creating a barrier to independence in performing essential activities or any occupations which require water, such as selfcare, cleaning or cooking food. Crawling to sanitation facilities is also unhygienic and harmful to a person's health and dignity. In addition, one village is having a problem with pollution and others question the quality of the water; pollution can be detrimental to health, increase the risk of disease and impairment and require a person to access more distant water sources. These environmental factors are consistent with findings in East Africa where such barriers in the physical environment hinder access, particularly for those with physical impairments in rural areas (WELL, 2006).

ii. Governance and lack of transparency is a barrier to development Access to water is also affected by political factors, particularly at a local level. Different participants identified different people that they believed had roles and responsibilities to supply and maintain the water services. One participant thought that it was the land owner's and chief's role (interview 2) whilst another supposed that it was the responsibility of "parliament and senior people" (interview 3). Another villager suggested that contractors were accountable for poor installation and service delivery and were effectively "robbing the government" (interview 8).

"The chief is the one who is supposed to solve the problems of this community, it is his, he should treat people fairly and provide good things for his people, who can renew this place if it is not him?" and "we are just residents of this place but the village has got its owner, he is the one who can take action about his people who are struggling, he can see that we are struggling, but he is the one who can stand up for his people and say that they are struggling." (interview 2) 
Interviewer: "As you are expecting that water taps should be installed at home, who do you think has the responsibility to do so?"

Interviewee: "We know that it should be people from the parliament and senior people in the government." (interview 3)

Whoever is responsible it is clear that some of the government water supply systems are faulty and unreliable, and the coping strategies that people employ may impact upon their opportunities for engaging with productive occupations. For example, one participant explained his decision to sell his cows and use the money to sink his own borehole, because of his progressive disability and the expense of buying water. $\mathrm{He}$ would supply water to neighbours without boreholes, but was reluctant to ask them to pay, and therefore had exchanged his productive occupation for some degree of water security which benefited himself and his neighbours in times of water scarcity.

Interviewer: "How were you coping with fetching water before you have water at home?"

Interviewee: "I use to pay."

Interviewer: "Was it very expensive for you or were you affording that?"

Interviewee: "It expensive for me."

Interviewer: "Did you make this borehole that you have here at home yourself?"

Interviewee: "We use to have cows here at home, by the time I realised that I was no longer able to look after them, I sold them (to pay for the borehole)." Interviewer: "She is saying that it looks like everyone in this community has a borehole at home (rather) than getting water from the communal taps in the streets?"

Interviewee: "Yes, but you cannot have a borehole if there is water at the communal taps in the streets, the reason we have boreholes is because it was difficult. Just imagine others may be able to have boreholes, but what would happen to those who cannot afford to have one? Here at my neighbours they do not have water, sometimes we get water from the government but it may take up to two or three weeks without water, but these people would come here and ask for water and we give them, sometimes when you think to make a person to pay for water is not fair." (interview 1) 
One village even raised money to address the problem, however the money seems to have got "lost" (interview 1). The same participant also explained that:

"The problem is that we cannot see where our development is going" (interview 1)

The participant went on to suggest that that local leaders are "blocking" development (interview 1). It seems therefore that political factors have played a role in access to water but that the role of various levels and types of governance in water management is not fully understood. It is also possible that some villagers face barriers to voicing concerns, for example one participant explained that he "keeps himself safe" by not involving himself in the community (interview 1). Political uncertainty and poor water management thus appears to have impacted on people's access to water, with direct effects on opportunities to maintain productive occupations, as illustrated in the case of a participant with progressive disability.

iii. People struggle to access or afford enough water for household and selfcare occupations

Access to water and sanitation also appears to be affected by socio-economic factors. Participants explain that they simply don't have the money to afford water. Whilst the government has been supplying water to some, it is reported to be "expensive" (interviews 1 and 2) and "not enough" (interviews 2, 4 and 5), and this was reported to impact on engagement with household and self-care activities. For example, two female participants (interviews 2,4) were retired from formal employment but had carer roles within their family, one cared for her grandchildren whilst their mother worked and the other was occupied as a full-time carer for her grandchild with severe disability. One older adult living alone (interview 5) specified that he could not access enough water to wash, affecting his self-care.

Interviewer: "Do you get enough water for the activities in the house when you fetch water from wherever you are getting it, that is either from the people or from the chief's place?"

Grandmother: "No it is not enough; I get only a few drums." (interview 2)

Interviewer: "If you may have water in your home, what is it that is going to change?" 
Grandmother: "There will be change because one may be able to plant things like carrots, spinach and onions so may have good health."

Interviewer: "Except for planting vegetables, what else can water help with if you have it in your home?"

Grandmother: "It would help to bath. Now we wash things with dirty water and put it aside and reuse it to wash pots; that is not a good thing to do." (interview 4).

"If there is no water there if I draw this two (2x 5 litre containers) I can bath and cook and to wash hands and legs, but to wash the body is not enough." (interview 5)

Socio-economic factors therefore impact on people's access to water and many who cannot afford water are "suffering" (interview 8). For older adults, persons with disabilities and carers of persons with disabilities there may be less opportunities to earn an income, which could affect them affording water.

"I would like to work, pension money is too little, and if anyone may come and request that I should come to clean/plough for them anywhere, I will not be able to go as I am looking after the child." (Interview 2)

Whilst some villagers have returned to their old ways of collecting water from rivers, others have resorted to stealing water. Participants report:

"There are people who are connecting water illegally and the water is not reaching our homes" and "Those who are able to get water now are not paying they are stealing" (interview 8)

Perhaps poverty is a trigger of this, causing those with a low income to rely on illegal connections, which can also impact on other people's access to water. Furthermore, the crime in some villages seems to have led to a lack of trust; "These days we no longer trust each other. "(interview 3). This has the potential to create divisions in the community at a time when unity is needed to address social problems.

iv. Attitudes create barriers to water access and impact upon caring occupations 
Attitudes towards disability also appear to affect people with disabilities or their carers accessing water. For example, in interview 4 a grandmother who was the sole carer of a child with disability stated "even if I may ask anyone to look after her, people do not accept disability, they think if they may look after her they will be transferring the disability to their families". Because of this attitude, she did not have any assistance to care for the child from friends, family or neighbours. Accessing water therefore meant leaving the child at home alone whilst she walked to the public standpipe and returned. She explained that this was not safe for the child;

Interviewee: "Except for looking after her, I have to go to the chief's place to fetch water using a wheel barrow, when I go to fetch water at the chief's place I have a very serious problem of leaving her alone in the house."

Interviewer: "What problem do you have when you have left her alone?" Interviewee: "My problem is that, these days it is no longer safe, I may have locked her inside the house and somebody may come and break in or burn the house, what people would say I have done, they would say I ran away from her."

Interviewer: "What you are saying is a problem is when you think of what may people do when you have left her alone, right?"

Interviewee: "Yes, when I have left her alone, because when you walk around you will hear people say that there is a child who alone in this house. You will hear older people thinking of doing bad things to a child who is unable to walk it is really bad."

This is consistent with findings by Groce et al. (2011) who report that people with disabilities often face stigma, abuse, discrimination and fears of contamination when using public and household facilities.

The interviews highlight factors affecting access to water and sanitation, particularly for people with disabilities and older adults. Due to discrimination and unequal access to resources and opportunities, people face challenges engaging with the occupations of daily life, indicating that there is occupational injustice. Indeed, across the set of interviews, the words "suffer" and "struggle" (and their suffixes) numerous times, reflecting the hardship these people are facing and the quality of their occupational performance. 


\section{Summary synthesis of semi-structured interviews and documentary analysis}

Findings from the interviews were synthesised with the documentary analysis findings, to develop a more comprehensive understanding of the broader historical context and how this has impacted on access to water and sanitation for people, particularly those with disabilities and older adults. Limited access to water and sanitation creates barriers to occupational engagement, which were discussed in relation to the basic daily activities of maintaining hygiene, safety and self-care as well as productive occupations. Figure 2 shows how the historical and current context (identified as factors in the documentary analysis) has impacted on the current barriers (identified as themes from the interviews), resulting in occupational injustice. The following section will expand on these results and will reflect on occupational justice.

\section{Discussion}

In this study we found that environmental factors (natural and man-made), the "legacy of the apartheid", and political, economic and social (including socio-economic and attitudinal) factors since the apartheid, have affected access to water and sanitation, and can create particularly challenging barriers for older adults or people with disabilities. Our findings are consistent with a recent study on water, sanitation and hygiene services (WASH) in Uganda and Zambia, which found that the main barriers for people with disabilities accessing these services were:

\section{"Environmental barriers: facilities are not inclusive}

Attitudinal barriers: negative attitudes lead to exclusion

Institutional barriers: lack of consultation or involvement in decision making on WASH policy” (Wilbur, 2014, p.2)

Our findings are also consistent with Groce et al. 's (2011) literature review, Jones and Reed's (2005) book and studies recently conducted in the same region (Geere et al., 2010a; Geere et al., 2010b; Majuru, 2015; Mudau, 2016). Indeed, participants reported environmental challenges such as hilly terrains and poor road conditions. The literature also revealed physical barriers in terms of facilities not catering for wheelchair users (Bannister, 2004) and having to travel large distances in rural areas to collect water (Francis, 2005). Both the interviews and literature revealed negative attitudes around "transferring" disability (Bannister, 2004), and the interviews also 
reported institutional barriers, where there was confusion over who was in charge and frustration over the lack of development.

However, the documentary analysis has added a new dimension, taking into consideration the historical factors that have caused these barriers, and providing more context and understanding of the political, economic and socio-cultural climate (see figure 2). For example, the interviews do not mention the apartheid, however the literature identifies the apartheid and its legacy as a key historical factor that has affected access to water and sanitation (Van Koppen and Jha, 2005; Brown, 2011, 2013; Francis, 2005). The geography of water was formed during the mining revolution and was entrenched during the apartheid regime (Francis, 2005; Brown, 2013). Such a regime created "separate development" where different environments developed side by side according to race (Van Koopen and Jha, 2005). Whilst attempts to undo the inequities of the past and redistribute water have been made, this has been in the context of neoliberalism with a decentralised participatory approach to water management (Brown, 2011). The approach has not been accessible to all groups, has lacked funding and has allowed de facto control of old actors to persist (Francis, 2005; Van Koopen and Jha, 2005; Brown, 2013). Lack of communication and poor consultation have been reported as the main barriers to good service delivery (Hosking and Jacoby, 2013) and poor service delivery, lack of access to water and inadequate sanitation have been reported to lead to social tension whereby communities resort to violence and unrest (Tapela, 2009). Similar issues of concern as a consequence of poor governance were highlighted in the interviews. Thus historical factors have contributed to the existing environmental, attitudinal and institutional barriers, perpetuating widespread poverty, inequality and occupational injustice.

\section{What are the occupational implications for people with disabilities and older adults?}

Occupational injustices (Stadnyk et al., 2011) have occurred in South Africa due to environmental, political, socio-economic and attitudinal factors affecting access to water and sanitation. Figure 2 demonstrates how historical and current contexts can impact on these factors, resulting in occupational injustice. In addition, the policy which allows practices established in the apartheid era to continue, because of the minimum standard to access water from off-plot supply points, has contributed to occupational injustice impacting on older adults and people living with disability 
(DWA, 1994). The terms occupational apartheid and occupational deprivation can be applied to South Africa's case and capture the type of occupational injustice that has occurred.

Occupational apartheid was most blatant during the apartheid era (Christiansen and Townsend, 2011, p.420), but has informally continued since the apartheid, for example where people with disabilities have not been included in sanitation policies or decision making processes. In South Africa some people have enjoyed unlimited access to water and sanitation facilities, whereas other people have experienced social exclusion and inadequate access to water and sanitation, resulting in deprived occupational participation (Stadnyk et al. 2011). In our interviews this was particularly apparent as insufficient water access for occupations essential to maintain health, well-being and dignity, such as bathing, washing and cooking. However, poor water access also limited capacity to maintain a safe environment to support caring occupations, which are commonly a responsibility of older adults in the region (Schatz \& Gilbert, 2014) or to maintain productive occupations, such as growing food or raising cattle, while living with disability or the effects of aging.

Pollard et al. (2009) asserted that South Africa's apartheid system is an extreme example of occupational apartheid, where occupations were restricted based on racial features. Indeed, the apartheid created physical, legal and social barriers in its separate development, producing a disabling environment with unequal access to water and sanitation. Furthermore, black people with disabilities had unequal access to employment, education and health care services and thus faced double discrimination (Dube, 2005). The occupational apartheid has perpetuated widespread poverty and as Hansen and Sait (2011) have argued, created dependency for people with disabilities. For example, in under resourced rural areas with poorly maintained, steep roads, wheel chair use can be impossible, and special equipment to suit the environment unaffordable. Thus limited mobility creates dependence on others for access to water when it must be collected away from home, and such dependence removes occupational choice and restricts occupational participation.

Indeed, many people have been dependent on the free basic water provided by the government. However, as highlighted by the findings, this free amount is "not enough" and deep inequalities, "suffering" and occupational deprivation persists. Whilst in wealthy areas some people use water for swimming pools and to irrigate 
gardens, in poorer areas water use and occupations are under constant scrutiny, where children are precluded from playing with water and have to restrict their daily water consumption (Von Schnitzler, 2008). Inadequate access to water and sanitation facilities in poor areas can also prevent children with disabilities going to school (Bannister, 2004; Groce et al. 2011), resulting in occupational deprivation. Collecting water takes time away from other occupations ( Geere et al., 2010a; Geere et al., 2010b) and self-care occupations such as bathing, cooking and cleaning are limited by the amount of water that can be carried, which people with disabilities or older adults may not be able to do. Such occupational injustice is a threat to health, wellbeing and dignity which then restricts opportunities to engage in other occupations that people value.

Despite becoming a democratic nation in 1994 there are still environmental, political, economic and social barriers affecting access to water and sanitation. Francis quoted Pilger when arguing that the dividing line is no longer about race but about class:

"Economic apartheid has replaced legal apartheid with exactly the same consequence for exactly the same people." (Pilger, 1998, cited in Francis, 2005).

Therefore poverty, a product of the apartheid, continues to be constructed by society creating unequal conditions and access to resources, thus causing occupational injustice. Not only is access to water and sanitation a human right but it should also be considered part of an occupational right, which allows people to participate in occupations that they choose, value and are meaningful to them.

\section{Limitations}

The use of an interpreter to communicate questions and answers during the interviews could have interrupted the flow of the conversation, leading to the truncation of answers. Furthermore, answers and questions could have also been misinterpreted or misunderstood, however full audio-recording and professional translation and transcription of the recordings into both Tshi-Venda and English were performed to mitigate this risk. The interviews took place in villages of one province, and may not be generalizable to other rural or urban areas in South Africa. 
The number of people interviewed with disability or who cared for someone with disability was small and additional participants may have provided more depth to the data about the challenges to water access faced by people with disability. However, our findings are consistent with themes reported by other researchers.

The search identified limited literature on access to sanitation and water for people with disabilities and older adults in South Africa, which could be a reflection of the limited research in this area. Some literature may have been missed due to the use of English language sources, however our electronic searches were not limited to English and should have identified papers published in languages other than English.

\section{Conclusions}

It is evident that there have been environmental, political, economic and social factors affecting access to water and sanitation in South Africa, particularly for people with disabilities or older adults who are poor. The interviews provided insight into the current factors affecting access to water and sanitation in a rural area. The documentary analysis identified the "legacy of the apartheid" as a key historical factor, and helped to provide a broader picture of some of the macro environmental factors that have affected the physical and social environment today. South Africa's past has created a disabling environment where occupational injustice has occurred in terms of occupational apartheid and occupational deprivation. The minimum standard for access to water described in current policy is a significant risk factor for occupational injustice affecting people with disabilities and older adults. Water supplies which are accessed off-plot or are unreliable, can create barriers to essential occupations, such as care of self and others, because of difficulties obtaining sufficient quantities of water for bathing, cooking and cleaning. The minimum standard level of service can also limit opportunities for more diverse or productive occupations, such as growing food, raising cattle, attending school or accepting formal employment. Further research is needed to identify factors and processes which facilitate or impede the translation of government plans for improving WASH access into action, and which support the realisation of health, social and economic benefits to enable the most vulnerable communities and community members to engage with essential, meaningful and productive occupations. Programmes which 
achieve occupational justice through better access to water will also facilitate achievement of many Sustainable Development Goals, by ensuring access to water and decent work for all to reduce poverty and inequality. 


\section{References:}

AMCOW. (2011). Water Supply and Sanitation in South Africa. Turning Finance into Services for 2015 and Beyond. Retrieved from http://www.wsp.org/sites/wsp.org/files/publications/CSO-SouthAfrica.pdf

Aveyard, H. (2014). Doing a Literature Review in Health and Social Care: A Practical Guide. Maidenhead: Open University Press.

Bannister, M. (2004). Disability and Gender in Rural Sanitation, People-centred Approaches to Water and Environmental Sanitation. Paper presented at the 30th WEDC International Conference, Vientiane, Lao.

Bartram, J., Lewis, K., Lenton, R., \& Wright, A. (2005). Focusing on improved water and sanitation for health. Lancet, 365(9461), 810-812.

Braun, V., \& Clarke, V. (2006). Using thematic analysis in psychology. Qualitative Research in Psychology, 3(2), 77-101.

Brown, J. (2011). Assuming too much? Participatory water resource governance in South Africa. The Geographical Journal, 177(2), 171-185.

Brown, J. (2013). Can Participation Change the Geography of Water? Lessons from South Africa. Annals of the Association of American Geographers, 103(2), 271-279.

Christiansen, C. H., \& Townsend, E. A. (2011). Introduction to Occupation: The Art of Science and Living (2nd ed.). London: Pearson Education International.

Coclanis, P. A. (2015). Introduction: Learning from history' In J. Bartram, R. Baum, P. A. Coclanis, D. M. Gutte, D. Kay, S. McFayden, K. Pond, W. Robertson, \& M. J. Rouse (Eds.), Routledge Handbook of Water and Health. London and New York Routledge.

Dube, A. K. (2005). The role and effectiveness of disability legislation in South Africa. Retrieved from http://r4d.dfid.gov.uk/PDF/Outputs/Disability/PolicyProject_legislation_sa.pd $\underline{f}$

DWA. (1994). Water supply and sanitation policy. Retrieved from https://www.dwaf.gov.za/Documents/Policies/WSSP.pdf. 
DWA. (2005). A history of the first decade of water service delivery in South Africa 1994-2004: Meeting the Mellenium Development Goals. Retrieved from https://www.dwa.gov.za/documents/publications/firstdecade.pdf.

Evans, B., Bartram, J., Hunter, P., Rhoderick Williams, A., Geere, J., Majuru, B., Bates, L., Fisher, M., Overbo, A., \& Schmidt, W. (2013). Public Health and Social Benefits of At-House Water Supplies. Available at: http://r4d.dfid.gov.uk/pdf/outputs/water/61005DFID_HH_water_supplies_fina 1_report.pdf (Accessed 18 October 2015).

Fewtrell, L., Kaufmann, R. B., Kay, D., Enanoria, W., Haller, L., \& Colford, J. M. (2005). Water, sanitation, and hygiene interventions to reduce diarrhoea in less developed countries: a systematic review and meta-analysis. Lancet Infect Dis, $5(1), 42-52$.

Francis, R. (2005) Water Justice in South Africa: Natural Resources Policy at the Intersection of Human Rights, Economics, and Political Power. Georgetown International Environmental Law Review, 18(1), pp. 149-196.

Geere, J. (2015). Health impacts of water carriage. In J. Bartram, R. Baum, P. A. Coclanis, D. M. Gute, D. Kay, S. McFayden, K. Pond, W. Robertson, \& M. J. Rouse (Eds.), Routledge Handbook of Water and Health. London and New York: Routledge.

Geere, J., Hunter, P. R., \& Jagals, P. (2010). Domestic water carrying and its implications for health: a review and mixed methods pilot study in Limpopo Province, South Africa. Environmental Health, 9, 52.

Geere, J. L., Mokoena, M. M., Jagals, P., Poland, F., \& Hartley, S. (2010). How do children perceive health to be affected by domestic water carrying? Qualitative findings from a mixed methods study in rural South Africa. Child Care Health Dev. 36(6), 818-26. doi: 10.1111/j.1365-2214.2010.01098.x.

Govender, P. E. (2014). Water and Sanitation, Life and Dignity: Accountability to People who are Poor. South African Human Rights Commission. Available at https://www.sahrc.org.za/home/21/files/FINAL\%204th\%20Proof\%204\%20M arch\%20-\%20Water\%20\%20Sanitation\%20low\%20res\%20(2).pdf (accessed 31 December 2016)

Groce, N., Bailey, N., Lang, R., Trani, J. F., \& Kett, M. (2011). Water and sanitation issues for persons with disabilities in low- and middle-income countries: a literature review and discussion of implications for global health and 
international development. J Water Health, 9(4), 617-627.

doi:10.2166/wh.2011.198.

Hansen, C., \& Sait, W. (2011). We too are disabled: disability grants and poverty politics' in rural South Africa. In A. H. Eide \& B. Ingstad (Eds.), Disability and poverty: a global challenge Bristol: Policy Press.

Hemson, D. (2007). The toughest of chores: policy and practice in children collecting water in South Africa. Policy Futures in Education, 5(3), 315-326.

Hoy, D., Geere, J., Davatchi, F., Meggitt, B., \& Barrero, L. H. (2014). A time for action: Opportunities for preventing the growing burden and disability from musculoskeletal conditions in low- and middle-income countries Best Practice \& Research in Clinical Rheumatology, 28(3), 377-393. doi:10.1016/j.berh.2014.07.006

Hosking, S. G. \& Jacoby, K. T. (2013). Trends in the insight into the growing South African municipal water service delivery problem. WRC Report No. 2087/1/P/13:1-35. Water Research Commission: South Africa, Pretoria.

Jones, H. E. (2013). Mainstreaming disability and ageing in water, sanitation and hygiene programmes. A mapping study carried out for WaterAid UK. Retrieved from http://www.wateraid.org/ /media/Publications/Mainstreamingdisability-and-ageing-in-water-sanitation-and-hygiene-programmes.pdf

Jones, H. E., \& Reed, R. A. (2005). Water and Sanitation for Disabled People and Other Vulnerable Groups: Designing services to improve accessibility Loughborough: Water Engineering and Development Centre.

Majuru, B. (2015). Unreliable water supplies and household coping strategies in periurban South Africa. (Unpublsihed doctoral thesis), University of East Anglia, Norwich.

Majuru, B., Jagals, P., \& Hunter, P. R. (2012). Assessing rural small community water supply in Limpopo, South Africa: Water service benchmarks and reliability. Science of The Total Environment, 435-436, 479-486. doi:http://dx.doi.org/10.1016/j.scitotenv.2012.07.024

Matsebe, G. (2006). 'Sanitation Policy in South Africa: Does it address People with Disabilities?', Sustainable Development of Water Resources, Water Supply and Environmental Sanitation: 32nd WEDC International Conference.

Colombo, Sri Lanka, 2006. Loughborough: Water Engineering Development Centre, pp. 533-536. 
Makaudze, E., du Preez, M., \& Potgieter, N. (2008). How does the HIV and AIDS epidemic in South Africa impact on Water, Sanitation and Hygiene Sectors? Retrieved from http://www.wrc.org.za/Knowledge\%20Hub\%20Documents/Research\%20Rep orts/1813-1-11.pdf

Moher D., Liberati A., Tetzlaff J., Altman D.G., The PRISMA Group (2009) Preferred Reporting Items for Systematic Reviews and Meta-Analyses: The PRISMA Statement. Public Library of Science Medicine 6(6): e1000097. doi:10.1371/journal.pmed1000097.

Molineux, M. (2010). The Nature of Occupation In Curtin, M., Molineux, M., and Supyk, J., (Eds) Occupational Therapy and Physical Dysfunction: Enabling Occupation (pp. 22). Edinburgh: Churchill Livingstone.

Mudau, S. L. (2016). Domestic Safe Water Management in Poor and Rural Households. (Unpublished doctoral thesis), Tshwane UNiversity of Technology, Pretoria.

Pollard, N., Sakellariou, D. \& Kronenburg, F. (2009) A Political Practice of Occupational Therapy. Philadelphia: Churchill Livingstone Elsevier.

Prüss-Üstün, A., Bos, R., Gore, F., \& Bartram, J. (2008). Safer water, better health: costs, benefits and sustainability of interventions to protect and promote health. Retrieved from Geneva:

Ritchie, J., \& Spencer, L. (1999). Qualitative data for applied policy research. In A. Bryman \& R. Burgees (Eds.), Analysis of Qualitative Data (pp. 173-194). London: Routledge.

Schatz, E., \& Gilbert, L. (2014). "My Legs Affect Me a Lot. ... I Can No Longer Walk to the Forest to Fetch Firewood": Challenges Related to Health and the Performance of Daily Tasks for Older Women in a High HIV Context. Health Care for Women International, 35(7-9), 771-788. doi:10.1080/07399332.2014.900064

Sen, A. (2001). Development as Freedom. Oxford: Oxford University Press.

Stadnyk, R.L., Townsend, E.A. \& Wilcock, A. (2011) Occupational Justice in Christiansen, C.H. and Townsend, E.A., Introduction to Occupation: The Art of Science and Living. 2nd edn, London: Pearson Education International, pp. 329-358. 
Statistics South Africa (2014). Census 2011: Profile of persons with disabilities in South Africa. Available at: http://beta2.statssa.gov.za/publications/Report-0301-59/Report-03-01-592011.pdf. (Accessed: 15 October 2015).

StatsSA (2014). General Household Survey, 2013. (Statistical release PO318).

Pretoria.

Tapela, B. N. (2012). Social water scarcity and water use. Water Research Commission (WRC) Report No. 1940/1/11:1-52. Pretoria, South Africa.

United Nations (2016). Sustainable Development Goals. Retrieved from https://sustainabledevelopment.un.org/?menu=1300

UNICEF, \& WHO. (2015). Progess on Sanitation and Drinking Water. 2015 Update and MDG Assessment. Retrieved from https://www.unicef.org/publications/index_82419.html

United Nations (2016). Sustainable Development Goals: Goal 6. Available at: http://www.un.org/sustainabledevelopment/water-and-sanitation/ (Accessed: 13 February 2016).

Van Koppen, B. \& Jha, N. (2005). 'Redressing racial inequities through water law in South Africa: Interaction and contest among legal frameworks' In Roth, D., Boelens, R. and Zwarteveen, M., (Eds) Liquid Relations: Contested Water Rights and Legal Complexity, New Brunswick, New Jersey: Rutgers University Press, pp. 195-214.

Von Schnitzler, A. (2008). 'Citizenship Prepaid: Water, Calculability, and TechnoPolitics in South Africa', Journal of Southern African Studies, 34(4), pp. 899917.

Wang, X., \& Hunter, P. R. (2010). A systematic review and meta-analysis of the association between self-reported diarrhoeal disease and distance from home to water source. American Journal of Tropical Medicine and Hygiene, 83(582584).

WaterAid. (2011). What the Global Disability Report means for the WASH sector. Briefing note.

WELL (2006) Why the water and sanitation sector in East Africa should consider disabled people. Available at: http://www.lboro.ac.uk/well/resources/Publications/Briefing\%20Notes/WELL \%20CN\%2012.1\%20East\%20Africa.pdf. (Accessed: 18 October 2015). 
Whalley Hammel, K. R., \& Iwama, M. K. (2012). Well-being and occupational rights: An imperative for critical occupational therapy. Scandinavian Journal of Occupational Therapy, 19, 385-394.

WHO. (2011). World Report on Disability. Retrieved from http://www.who.int/disabilities/world_report/2011/report.pdf

Wilbur, J. (2014). Undoing inequity WASH programmes that deliver for all in Uganda and Zambia. Poster presentation at the Water, Sanitation and Hygiene for Everyone, Everywhere Conference, Brisbane, Australia.

Wilcock, A., \& Townsend, E. (2000). Occupational Justice. Occupational therapy interactive dialogue. American Journal of Occupational Therapy, 7, 84-86.

Wilcock, A. A., \& Townsend, E. A. (2009). Occupational Justice. In E. B. Crepeau, E. S. Cohn, \& B. S. B. A. (Eds.), Willard \& Spackman's Occupational Therapy (11th ed., pp. 193-199). Baltimore: Lippincott Williams \& Wilkin.

Wolf, L., Ripat, J., Davis, E., Becker, P.,, \& MacSwiggan, S. (2010). Applying an occupational justice framework. Occupational Therapy Now, 1, 15-18. 


\section{Figures}

Figure 1: Adapted PRISMA (Preferred Reporting Items for Systematic Reviews and Meta-Analyses) flowchart (Moher et al. 2009):

Figure 2: Summary of findings 
Appendix 1.

Table 1 Summary of the literature

\begin{tabular}{|c|c|c|c|c|}
\hline Author & $\begin{array}{l}\text { Type of } \\
\text { source }\end{array}$ & Aim of Literature & Key findings & Strengths and limitations \\
\hline $\begin{array}{l}\text { Bannister } \\
(2004)\end{array}$ & $\begin{array}{l}\text { Conference } \\
\text { paper }\end{array}$ & $\begin{array}{l}\text { To define disability and } \\
\text { gender needs and to } \\
\text { discuss how they can be } \\
\text { incorporated into } \\
\text { sanitation programmes. }\end{array}$ & $\begin{array}{l}\text { People with disabilities' needs are } \\
\text { not always being considered. More } \\
\text { awareness is needed to improve } \\
\text { infrastructure, hygiene and safety } \\
\text { for all. }\end{array}$ & $\begin{array}{l}\text { The paper highlights some gender and } \\
\text { disability issues. However, these are based on } \\
\text { personal experiences in one rural area. }\end{array}$ \\
\hline $\begin{array}{l}\text { Brown } \\
(2011)\end{array}$ & $\begin{array}{l}\text { Empirical } \\
\text { research }\end{array}$ & $\begin{array}{l}\text { To explore the } \\
\text { institution-alisation of } \\
\text { participatory water } \\
\text { resource management in } \\
\text { post-apartheid South } \\
\text { Africa. }\end{array}$ & $\begin{array}{l}\text { There are weaknesses in the } \\
\text { participatory model. There is a need } \\
\text { for a reassessment of the role of the } \\
\text { state, where greater intervention } \\
\text { could support the interests of } \\
\text { marginalised groups. }\end{array}$ & $\begin{array}{l}\text { The paper uses empirical research to explore } \\
\text { participatory water management, but the } \\
\text { methodology is not discussed in detail, and it } \\
\text { is unclear whether it can be applied to other } \\
\text { areas in South Africa. }\end{array}$ \\
\hline $\begin{array}{l}\text { Brown } \\
\text { (2013) }\end{array}$ & $\begin{array}{l}\text { Empirical } \\
\text { research }\end{array}$ & $\begin{array}{l}\text { To evaluate the potential } \\
\text { of both participation and } \\
\text { institutional reform to } \\
\text { change the geography of } \\
\text { water in South Africa. }\end{array}$ & $\begin{array}{l}\text { Participation has not changed the } \\
\text { geography of water. There is a need } \\
\text { for state-directed water resource } \\
\text { management. }\end{array}$ & $\begin{array}{l}\text { Brown uses the same research from the } 2011 \\
\text { study. Brown states research is 'rigorous' but } \\
\text { doesn't explain how rigor was achieved. }\end{array}$ \\
\hline $\begin{array}{l}\text { Francis } \\
(2005)\end{array}$ & $\begin{array}{l}\text { Periodical / } \\
\text { scholarly } \\
\text { review }\end{array}$ & $\begin{array}{l}\text { To explore the history of } \\
\text { water law and policies, } \\
\text { and analyse the legal } \\
\text { right to water. }\end{array}$ & $\begin{array}{l}\text { Suggests a need for civil society to } \\
\text { coerce policymakers into amending } \\
\text { existing laws to redistribute water, } \\
\text { thereby alleviating inequalities and } \\
\text { injustices. }\end{array}$ & $\begin{array}{l}\text { The paper uses a variety of sources and } \\
\text { provides an environmental law perspective. } \\
\text { However, it does not evaluate the quality of } \\
\text { the sources or explain how the sources were } \\
\text { found. }\end{array}$ \\
\hline $\begin{array}{l}\text { Matsebe } \\
\text { (2006) }\end{array}$ & $\begin{array}{l}\text { Conference } \\
\text { paper }\end{array}$ & $\begin{array}{l}\text { To review sanitation } \\
\text { policies and their }\end{array}$ & $\begin{array}{l}\text { People with disabilities have been } \\
\text { excluded from sanitation policies. } \\
\text { Matesbe suggests introducing }\end{array}$ & $\begin{array}{l}\text { The paper offers a succinct overview of how } \\
\text { people with disabilities are excluded from } \\
\text { sanitation policies. }\end{array}$ \\
\hline
\end{tabular}




\begin{tabular}{|c|c|c|c|c|}
\hline & & $\begin{array}{l}\text { inclusion of people with } \\
\text { disabilities. }\end{array}$ & $\begin{array}{l}\text { economic measures such as } \\
\text { subsidies, incentives and fines. }\end{array}$ & \\
\hline $\begin{array}{l}\text { Van } \\
\text { Koppen } \\
\text { and Jha, } \\
(2005)\end{array}$ & $\begin{array}{l}\text { Book } \\
\text { chapter }\end{array}$ & $\begin{array}{l}\text { To review attempts to } \\
\text { redress racial inequities } \\
\text { through water law, } \\
\text { exploring the interaction } \\
\text { between legal } \\
\text { frameworks. }\end{array}$ & $\begin{array}{l}\text { The National Water Act (1998) has } \\
\text { the potential to redress inequalities } \\
\text { but old laws, the power of old } \\
\text { rulers and poor technical leaders } \\
\text { are hindering progress. }\end{array}$ & $\begin{array}{l}\text { The authors consider the interaction between } \\
\text { legal frameworks and uses a case study } \\
\text { example. However, they acknowledge that } \\
\text { some evidence is fragmentary. }\end{array}$ \\
\hline $\begin{array}{l}\text { Von } \\
\text { Schnitzler } \\
(2008)\end{array}$ & $\begin{array}{l}\text { Scholarly } \\
\text { review } \\
\text { with some } \\
\text { empirical } \\
\text { evidence }\end{array}$ & $\begin{array}{l}\text { To investigate 'Operation } \\
\text { Gcin'samanzi' (a project } \\
\text { initiated by Johannesburg } \\
\text { Water) and to provide a } \\
\text { history of prepayment } \\
\text { technology }\end{array}$ & $\begin{array}{l}\text { Suggests that prepayment meters } \\
\text { are political tools under the guise of } \\
\text { a life line tariff, which force } \\
\text { citizens scrutinize their daily } \\
\text { practices and consumption of } \\
\text { water. }\end{array}$ & $\begin{array}{l}\text { The paper provides an urban perspective, } \\
\text { which affects over five million people. } \\
\text { However, this is not representative of the } \\
\text { whole population. Furthermore, the } \\
\text { methodology is not fully explained. }\end{array}$ \\
\hline
\end{tabular}


Table 2. Themes and key supportive quotes

\begin{tabular}{|c|c|c|c|}
\hline Factor & Theme & $\begin{array}{l}\text { Interview number } \\
\text { (participant description) }\end{array}$ & Quote \\
\hline \multirow[t]{4}{*}{ Environment } & \multirow{4}{*}{$\begin{array}{l}\text { Environment } \\
\text { impacts on } \\
\text { ease of water } \\
\text { access and } \\
\text { water quality }\end{array}$} & $\begin{array}{l}5 \text { (Elderly man living alone; } \\
\text { low income) }\end{array}$ & $\begin{array}{l}\text { "It is difficult to climb this hill. I cannot carry because of this hill, if it is a flat } \\
\text { area you can put them in a wheelbarrow" }\end{array}$ \\
\hline & & $\begin{array}{l}8 \text { (Group meeting with older } \\
\text { women; } 5 \text { participants) }\end{array}$ & $\begin{array}{l}\text { "It is a challenge for those who stay over the hill, they are suffering, it could be a } \\
\text { month and going to the second month without water here, even the taps are not } \\
\text { repaired and we are suffering we have just returned to our old ways of doing } \\
\text { things" }\end{array}$ \\
\hline & & 8 & $\begin{array}{l}\text { "There is something that I need to explain, I had developed a culture of avocados } \\
\text { using water at my home, when I got the tap in my home in the beginning when I } \\
\text { was still working I planted the avocado trees and even ploughing at an empty } \\
\text { space and I was able to water the plants using that tap. Now I am suffering, I am } \\
\text { an elderly person, now I can no longer carry the bucket of water and there is no } \\
\text { water at the reservoirs, when water comes, it would only reach this house and not } \\
\text { the next house, there are people who are connecting water illegally and the water } \\
\text { is not reaching our homes and we do not know what to do anymore, some day we } \\
\text { get the water and would fill the drums and buckets to their capacity, we had to } \\
\text { buy drums for water." }\end{array}$ \\
\hline & & $\begin{array}{l}7 \text { (Group meeting with older } \\
\text { men; } 6 \text { participants) }\end{array}$ & $\begin{array}{l}\text { Interviewee: "It is water shortage, all these taps do not have water and it is already } \\
\text { a month now without water." } \\
\text { Interviewer: "Does this happen everytime or is it just happening now?" } \\
\text { Interviewee: "It happens most of the times, the machines that have been placed } \\
\text { initially have been placed down and when they have to make pressure to pump } \\
\text { water up they always break down." } \\
\text { Interviewer: "Where do you normally get water?" } \\
\text { Interviewee: "It is at the main river." }\end{array}$ \\
\hline
\end{tabular}


Interviewee "They have problems those people because they fetch water down the hills, you must also remember that when they fetch water down the hills and take it up the hills they encounter problems, after some years you would hear people complaining about their backs."

Interviewer: Do they have any challenges with the capacity of water that they are taking home?

Interviewee: It has a very big problem because they will have to cook, wash and bath and at the same time they are using 20 litre containers."

\begin{tabular}{|c|c|}
\hline 8 & "I am an elderly person now I can no longer carry the bucket of water" \\
\hline $\begin{array}{l}3 \quad \text { (Grandmother; low } \\
\text { income) }\end{array}$ & $\begin{array}{l}\text { "The road is not in good condition... They have been damaged by water, they } \\
\text { have potholes" }\end{array}$ \\
\hline 7 & "There are so many potholes." \\
\hline $\begin{array}{l}6 \text { (Carer of a child with a } \\
\text { disability) }\end{array}$ & $\begin{array}{l}\text { "If she is forced to go there she crawls with her knees... What I was thinking of } \\
\text { is to have a path so that she can use to move around." }\end{array}$ \\
\hline 7 & "We have a problem with people who pollute." \\
\hline 1 (Person with a disability) & $\begin{array}{l}\text { "We are forced to drink this water if we do not have the municipality water but } \\
\text { is very salty." }\end{array}$ \\
\hline 8 & $\begin{array}{l}\text { "Now we are drinking the water from the springs... they will find many diseases } \\
\text { in us" }\end{array}$ \\
\hline 1 & "The problem is that we cannot see where our development is going" \\
\hline $\begin{array}{l}2 \quad \text { (Grandmother and } \\
\text { granddaughter; low income) }\end{array}$ & "It the responsibility of land owners. The chief is the one who can say." \\
\hline 3 & $\begin{array}{l}\text { "We know that it should be people from the parliament and senior people in the } \\
\text { government." }\end{array}$ \\
\hline 8 & $\begin{array}{l}\text { "People who put up that reservoir has used old pipes that were put underground } \\
\text { but it was a contractor, it means that they have robbed the government". }\end{array}$ \\
\hline 8 & $\begin{array}{l}\text { "The taps are not repaired and we are suffering we have just returned to our old } \\
\text { ways of doing things." }\end{array}$ \\
\hline
\end{tabular}




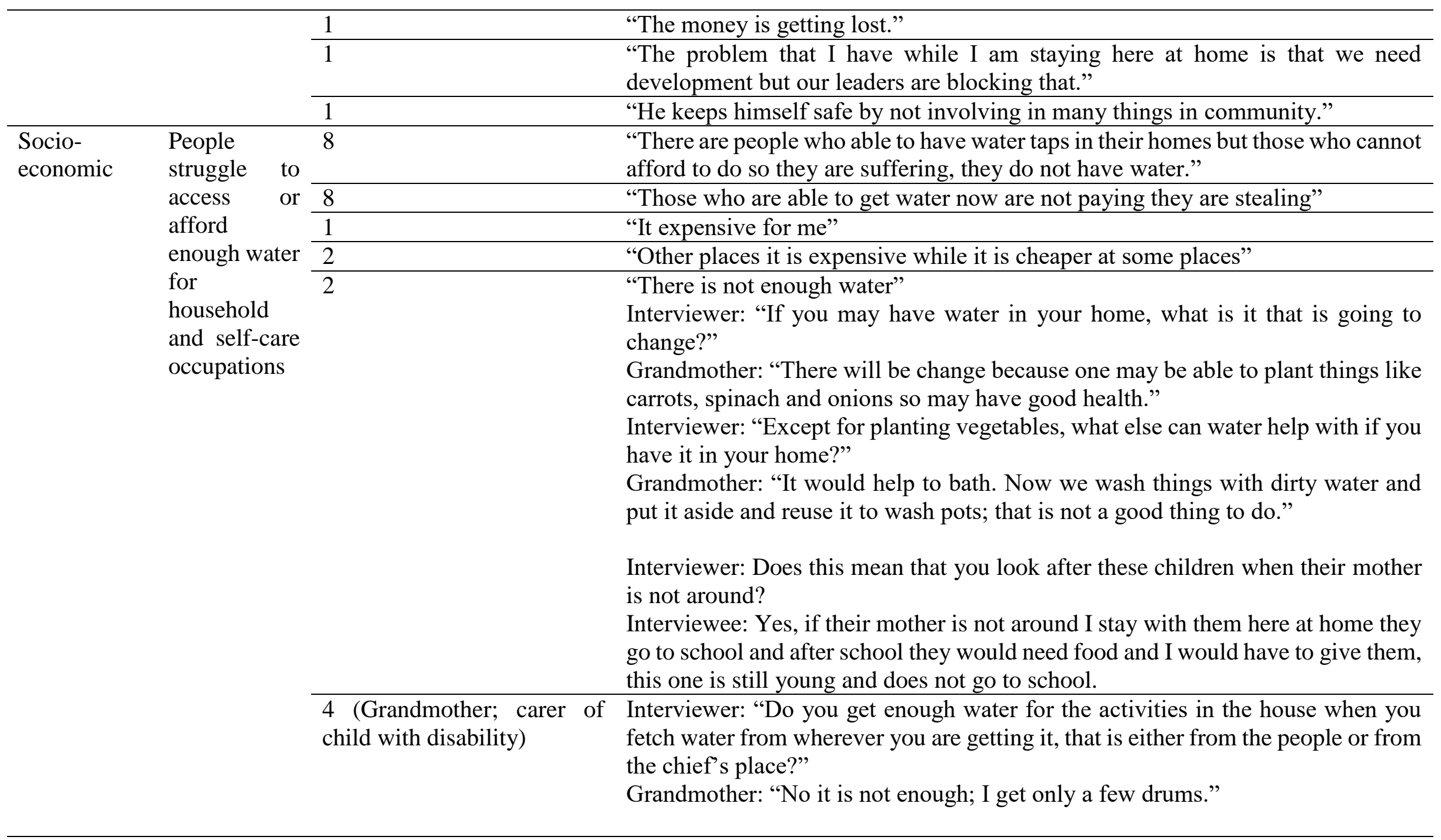




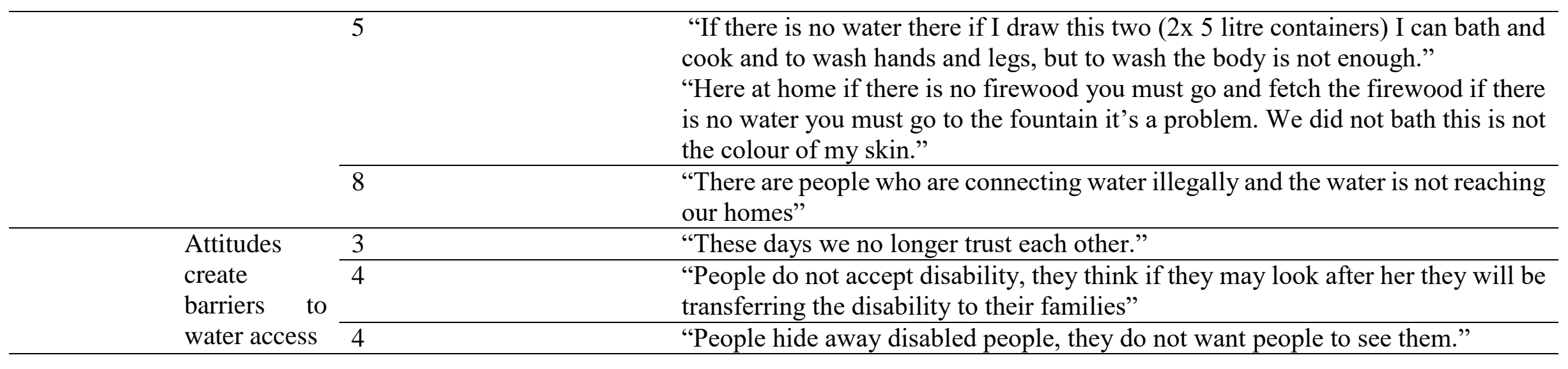

